\title{
Evaluation of induced residual stresses on AISI 1020 low carbon steel plate from experimental and FEM approach during TIG welding process
}

\author{
I. B. Owunna and A. E. Ikpe ${ }^{1}$ \\ Department of Mechanical Engineering, University of Benin, \\ PMB 1154, Edo State, Nigeria \\ Phone: +2349024773812 \\ ${ }^{1}$ Email: ikpeaniekan@gmail.com
}

\begin{abstract}
Induced residual stresses on AISI 1020 low carbon steel plate during Tungsten Inert Gas (TIG) welding process was evaluated in this study using experimental and Finite Element Method (FEM). The temperature range measured from the welding experimentation was $2511^{\circ} \mathrm{C}-423^{\circ} \mathrm{C}$, while the temperature range measured from the FEM was $230^{\circ} \mathrm{C}-563^{\circ} \mathrm{C}$; whereas, the residual stress range measured from the welding experimentation was $144 \mathrm{MPa}-$ 402Mpa, while the residual range measured from the FEM was $233-477 \mathrm{MPa}$ respectively. Comparing the temperature and stress results obtained from both methods, it was observed that the range of temperature and residual stresses measured were not exactly the same due to the principles at which both methods operate but disparities between the methods were not outrageous. However, these values can be fed back to optimization tools to obtain optimal parameters for best practices. Results of the induced stress distribution was created from a static study where the thermal results were used as loading conditions and it was observed that the temperature increased as the von-Mises stress increased, indicating that induced stresses in welded component may hamper the longevity of such component in service condition. Hence, post-weld heat treatment is imperative in order to stress relieve metals after welding operation and improve their service life.
\end{abstract}

Keywords: Residual stress; failure; welded joint; welding temperature; flat plate.

\section{INTRODUCTION}

The application of steel plays a vital role in the assembly of vehicular structures, as high strength material is used in the critical regions such as A and B pillars, fuel tank guard, bumper beam etc. but low strength material is used in the areas with less critical regions/geometry for the purpose of reducing the weight of a vehicle which in turn increases fuel economy without compromising the structural integrity of the car [1]. However, the application of high strength steels in automotive industry has been on the high side for centuries [2], but low carbon steels have also had its application in chassis and body panel of every road-worthy vehicles ranging from standard five-seaters to heavy duty trucks due to its high cost benefit, weldability, malleability, formability, high potential to be engineered in several ways to meet crash safety requirements etc. According to Razak and Shing [3], carbon 
steel is the most widely used engineering material and despite its low corrosion resistant property is still applicable in marine industries, construction and automotive industries, chemical and petroleum industries etc.

However in vehicle manufacturing sequence, it is vital to achieve high quality welds which depends on the type of welding, welding parameters, mechanical properties of welded metal, all of which influences the metallurgical and thermal behaviour of the material during welding process [4]. Investigation on the effects of process parameters on mechanical properties of spot welded low carbon steel indicated that welding current has a major influence on the mechanical property of a welded metal due to the thermal load resulting from current flow through the electrode which depending on the current increases the heat input [5], thereby inducing thermal stress on the weldment. Prior to technological advancement in production and manufacturing process in early 1920s, Tungsten Inert Gas (TIG) welding processes had not gain much popularity because it was a grey area that required further development but its application and relevance in many industries in recent times have increased significantly due to cost savings and reliability [6].

However, residual stress has a negative effects on the service condition of any given component manufactured through fusion welding process such as tungsten inert gas welding, particularly the tensile residual stress distribution which stimulates the nucleation and propagation of fatigue cracks over time. According to Ravichandran et al. [7], TIG is an arc metal welding process that is used in the fusion of two or more metals together by heating them with an arc between a non-consumable electrode and the welded metal. Deng et al. [8] in their investigation used Finite Element $(\mathrm{FE})$ method to predict the residual stresses induced in the weldment of tungsten inert gas arc welding process. The results indicated that phase transformation due to heat transfer across the weldment can alter the microstructure of the material, thereby, contributing to induced residual stresses on low carbon steel plates. Tsai and Kim [9] suggested that the cooling phase rather than heating sequence has a decisive influence on the formation of residual stresses. Radaj [10] pointed out that the cooling process below half the melting temperature can begin to indicate changes in the material weldment with gradual formation of internal stresses depending on the material properties. Zain-ulAbdein et al. [11] developed an FE model to analyse induced residual stresses due to thermal effect of laser-welding process on the material. The results revealed that the longitudinal residual stress has a significant effect on the distortion and failure characteristics of the welded component in relation to the transverse and through-thickness residual stresses.

The thermal and thermo-elasto-plastic variations during welding process usually considers the non-linearities resulting from phase transformation and transformation plasticity, microscopic plastic flow that occurs during phase transformations, variation of material properties and heat transfer coefficients with temperature as well as the inclusion of radiative boundary condition and solid phase transformation effects. Residual stresses are important in the consideration of cracking and fracture phenomenon in welded component, as accurate evaluation of their behaviour and response to the aforementioned transformations can go a long way in solving problems such as intergranular stress corrosion cracking, which may be found in the weld fusion lines of some welded component [12-14]. Mohamed et al. [15] reported that the behaviour of crack initiation until the fracture phase of a given metal under multiaxial stress condition is quite different from that of uniaxial stress condition, but both stress condition eventually result in fatigue damage which occurs depending on the direction of principal stress induced during loading by a number of independent forces. 
Taylor et al. [16] explain that the thermal transient simulation of welding process can occur in two ways namely; the complex fluid and thermo-dynamics local to the weld pool are modelled by closely observing possible changes in the weld pool and the Heat Affected Zone (HAZ).

In this case, the conservation of mass, momentum and heat alongside the latent heat and surface tension boundary conditions are equated to delineate the physical condition of the molten weld pool and thermal behaviour of the HAZ. Secondly, the solid mechanics method which is obtained by modelling the global thermo-mechanical response of the weld structure, focusing on the heat source. A number of simplified heat source models can be adopted for the simulation of welding process and its accuracy which depends on the empirical parameters that represents the weld pool size and shape [17], but the heat source in this study was modelled using Goldak model as proposed by Goldak and Akhlaghi [18] and Goldak et al. [19].

This study is focused on the evaluation of induced residual stress distributions on AISI 1020 low carbon steel plate using experimental and FEM TIG welding approach. In this case, the same set of input variable applies to both approaches, after which, the output response(s) is graphically compared to determine possible variations and accuracy of FEM approach in welding applications.

\section{MATERIALS AND METHOD}

In this section, the various materials used in the welding experimentation and the finite element analysis as well as the governing equations were stated and described appropriately according to its relationship with the welding sequence.

\section{Materials}

Equipment used to achieve the aim of this study includes; power saving machine for cutting the materials, vertical milling machine for milling the angles, G-clamp for clamping the work pieces, welding machine, welding electrode, thermocouple, $10 \mathrm{~mm}$ flat plate, SOLIDWORKS software.

\section{Method}

A $10 \mathrm{~mm}$ thickness of AIS1 1020 low carbon steel was sourced locally and was cut to a dimension of $60 \times 30 \mathrm{~mm}$ (length $\mathrm{x}$ width) each. Sand paper was used to smoothen each of the two specimen to eliminate all possible coatings, corrosion or rust that may have accumulated on the material. The two steel plates where chamfered at 30 degrees, after which, fusion welding was used to join the two plates together to form an angle of 60 degree with $2 \mathrm{~mm}$ depth. The milling of the angle was done using a vertical milling machine. The welding was carried out with the plates properly clamped to avoid misalignment during welding process. Prior to welding, surface of the samples to be welded were chemically cleaned with acetone to eliminate surface contamination and welding was applied on the flat plates. The welding parameters were deduced from design of experiment and were used in carrying out the welding process for 20 runs with variable voltages ranging from $16-25 \mathrm{~V}$, variable currents ranging from 96-213A and variable Gas Flow Rates (GFR) ranging from 11-19 L/min respectively. Parameters and welding specification used for the TIG Welding Process are 
presented in Table 1 while selected welding specimens with the welding parameters indicated are shown in Figure 1.

Table 1. Parameters and welding specification used for the TIG welding process.

\begin{tabular}{|c|c|c|c|}
\hline $\mathbf{S} / \mathbf{N}$ & Material Specification & \multicolumn{2}{|l|}{ Welding Specification } \\
\hline 1 & Welding Type & \multicolumn{2}{|l|}{ Tungsten Inert Gas (TIG) } \\
\hline 2 & Material & \multicolumn{2}{|l|}{ AISI 1020 Low Carbon Steel Plate } \\
\hline 3 & Gas Flow Rate (I/min) & \multicolumn{2}{|l|}{$11,13,15,18$ and 19} \\
\hline 4 & Voltage (V) & \multicolumn{2}{|l|}{$16,19,22,25,27$} \\
\hline 5 & Current (A) & \multicolumn{2}{|l|}{$96,120,155,190,213$} \\
\hline 7 & Material Thickness & \multicolumn{2}{|l|}{$10 \mathrm{~mm}$} \\
\hline 8 & Filler Material & \multicolumn{2}{|l|}{ ER $70 \mathrm{~S}-6$} \\
\hline 9 & Joint Type & \multicolumn{2}{|l|}{ Butt Joint (V-groove) } \\
\hline 10 & Joint Preparation & \multicolumn{2}{|l|}{ Abrasive Clean/Acetone Wipe } \\
\hline 11 & Joint Gap & \multicolumn{2}{|l|}{$2 \mathrm{~mm}$} \\
\hline 12 & Welding Current & $\begin{array}{l}\text { D.C.E.N (Direct } \quad \text { Current } \\
\text { Negative) }\end{array}$ & Electrode \\
\hline 14 & Filler Rod Angle & \multicolumn{2}{|l|}{$15^{\circ}$} \\
\hline 15 & Welding Torch Angle & \multicolumn{2}{|l|}{$45^{\circ}$} \\
\hline 17 & Torch Type & \multicolumn{2}{|l|}{ Pro-torch (TIG Torch) } \\
\hline 19 & Tungsten Type & \multicolumn{2}{|l|}{$2 \%$ thoriated } \\
\hline 20 & Tungsten Size & \multicolumn{2}{|l|}{ 3/1326" Diameter x $25.4 \mathrm{~mm}$} \\
\hline 21 & Torch Gas & \multicolumn{2}{|l|}{ Argon $(100 \%)$} \\
\hline 22 & Heat Input Ratio & \multicolumn{2}{|l|}{$10.75 \mathrm{KJ} / \mathrm{min}$} \\
\hline
\end{tabular}
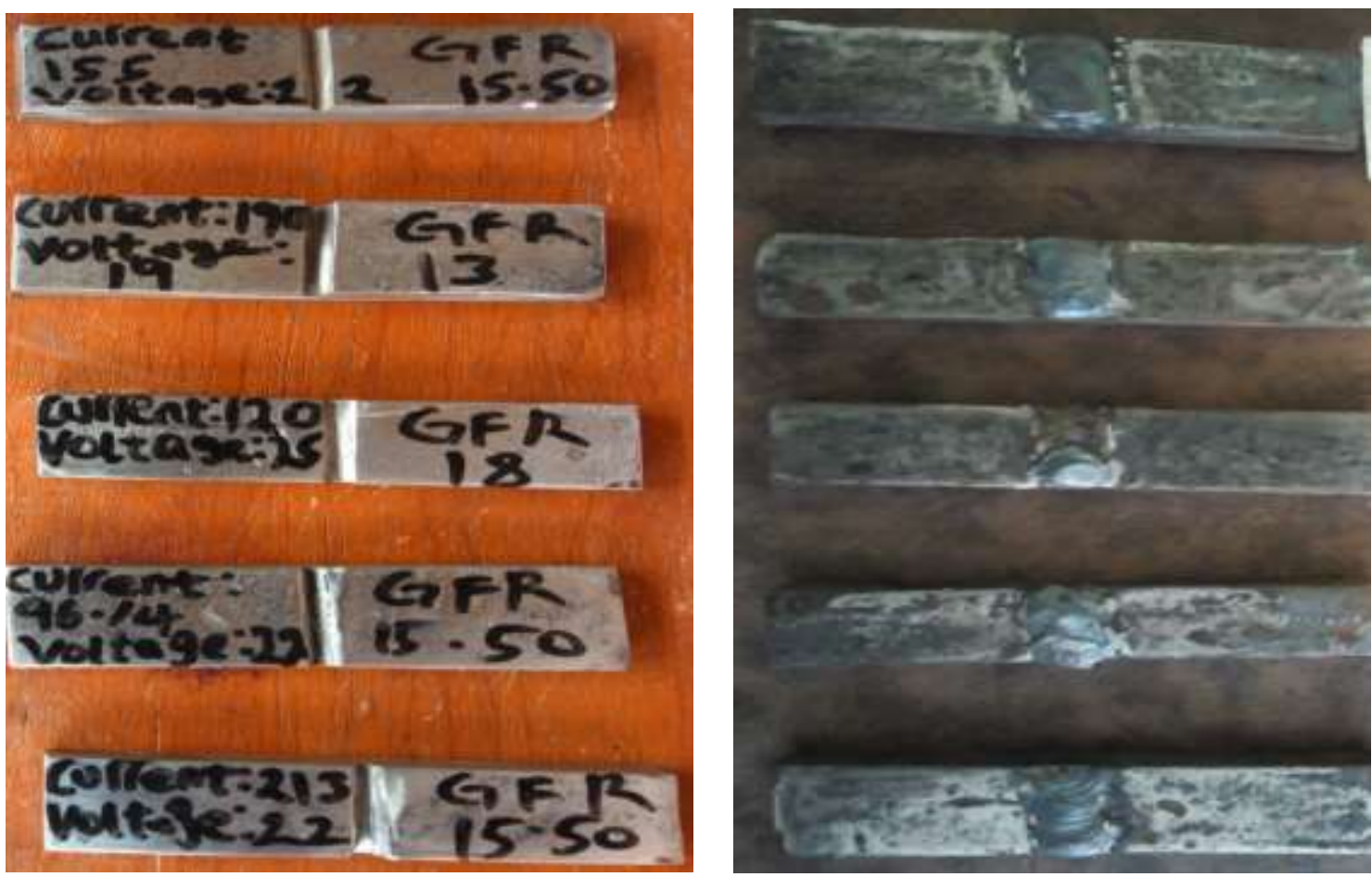

Figure 1. Samples before and after welding. 
A strain gauge was used to measure the residual stresses induced in the steel plate as a result of the heat source and parametric variations. The measured strain gauge values obtained from the experimentation were multiplied by the Young's modulus of the material to arrive at the induced stress. K-type thermocouples were attached to the surface of the workpiece and the temperature was recorded at 20 points as the arc passed along the workpiece. Also, the welding torch passed over the plate at a height of $2.5 \mathrm{~mm}$ from the workpiece at constant velocity of $1.72 \mathrm{~mm} / \mathrm{s}^{-1}$.

The moving heat source was modeled according to Goldak model [19]. From the Goldak heat source model [19], the volumetric heat flux for a point in the domain $\Omega$ is given by equation 1 ;

$$
q_{G}(x, y, \xi)=\left\{\begin{array}{l}
\frac{6 \sqrt{3 Q r_{f}}}{a b c_{f} \pi \sqrt{\pi}} \exp \left[-3\left(\frac{x^{2}}{a^{2}}+\frac{y^{2}}{b^{2}}+\frac{\xi^{2}}{c_{f}^{2}}\right)\right] \forall(x, y, \xi \geq 0) \in \Omega \\
\frac{6 \sqrt{3 Q r_{r}}}{a b c_{r} \pi \sqrt{\pi}} \exp \left[-3\left(\frac{x^{2}}{a^{2}}+\frac{y^{2}}{b^{2}}+\frac{\xi^{2}}{c_{f}^{2}}\right)\right] \forall(x, y, \xi<0) \in \Omega
\end{array}\right.
$$

Where, $r_{f}$ and $r_{r}$ are the heat input proportions in the front and rear ellipsoid quadrants, $Q$ is the energy input rate from the arc given by equation 2, $a b c_{r}$ and $c_{f}$ represent the radii of the flux distribution.

$$
Q=\eta V I
$$

Where, $\eta V$ and $I$ represent the efficiency, arc voltage and arc current.

During welding operation, temperature variation across the workpiece may result in expansion or retraction. The thermal effects as proposed by hooks law is given by the relationship in equation 3;

$$
\left[\begin{array}{c}
\varepsilon_{x x} \\
\varepsilon_{y y} \\
\varepsilon_{z z} \\
\Upsilon_{x y} \\
\Upsilon_{x z} \\
\Upsilon_{y z}
\end{array}\right]=\frac{1}{E}\left[\begin{array}{cccccc}
1 & -v & -v & 0 & 0 & 0 \\
-v & 1 & -v & 0 & 0 & 0 \\
-v & -v & 1 & 0 & 0 & 0 \\
0 & 0 & 0 & (1+v) & 0 & 0 \\
0 & 0 & 0 & 0 & (1+v) & 0 \\
0 & 0 & 0 & 0 & 0 & (1+v)
\end{array}\right]\left[\begin{array}{c}
\sigma_{x x} \\
\sigma_{y y} \\
\sigma_{z z} \\
\sigma_{x y} \\
\sigma_{x z} \\
\sigma_{y z}
\end{array}\right]+\alpha \Delta T\left[\begin{array}{l}
1 \\
1 \\
1 \\
0 \\
0 \\
0
\end{array}\right]
$$

Equation 3 can be expressed inversely as given by equation 4;

$$
\left[\begin{array}{c}
\sigma_{x x} \\
\sigma_{y y} \\
\sigma_{z z} \\
\sigma_{x y} \\
\sigma_{x z} \\
\sigma_{y z}
\end{array}\right]=\overline{\bar{K}}\left[\begin{array}{c}
\varepsilon_{x x} \\
\varepsilon_{y y} \\
\varepsilon_{z z} \\
2 \varepsilon_{x y} \\
2 \varepsilon_{x z} \\
2 \varepsilon_{y z}
\end{array}\right]-\frac{E \alpha \Delta T}{1-2 v}\left[\begin{array}{l}
1 \\
1 \\
1 \\
0 \\
0 \\
0
\end{array}\right]
$$

The governing partial differential equation for the transient heat conduction is given by equation 5

$$
\left.K(T)\left(\partial^{2} T / \partial x^{2}\right)+\left(\partial^{2} T / \partial y^{2}\right)+\left(\partial^{2} T / \partial z^{2}\right)+Q=\rho(T) C_{P}(T)\right) \partial T / \partial t
$$


Where, $x, y, z$ represents the Cartesian coordinates, $Q$ is the internal heat generated, $\rho$ is the density, $k$ is the thermal conductivity, and $C_{p}$ is the specific heat, are functions of the welding temperature, $T$.

The total strain within the material after TIG welding operation must satisfy the following compatibility condition in equation 6 ;

$$
\left[\frac{\partial^{2} \varepsilon_{x}^{\prime}}{\partial y^{2}}+\frac{\partial^{2} \varepsilon_{y}^{\prime}}{\partial x^{2}}-\frac{\partial^{2} \gamma_{x y}^{\prime}}{\partial x \partial y}\right]+\left[\frac{\partial^{2} \varepsilon_{x}^{\prime \prime}}{\partial y^{2}}+\frac{\partial^{2} \varepsilon_{y}^{\prime \prime}}{\partial x^{2}}-\frac{\partial^{2} \gamma_{x y}^{\prime \prime}}{\partial x \partial y}\right]=0
$$

In cases where the total strain within the material after TIG welding operation do not satisfy the compatibility conditions expressed in equation 6 , such condition is known as the incompatibility term " $R$ ", which can be determined by plastic strain. When the value of $R$ is not zero, then residual stresses may likely exist in the weldment. In this case, $R$ is given by equation 7;

$$
R=-\left[\frac{\partial^{2} \varepsilon_{x}^{\prime \prime}}{\partial y^{2}}+\frac{\partial^{2} \varepsilon_{y}^{\prime \prime}}{\partial x^{2}}-\frac{\partial^{2} \gamma_{x y}^{\prime \prime}}{\partial x \partial y}\right]
$$

For the FEM, the standard AISI 1020 was used for the modelling the low carbon steel plate considering the temperature dependent properties of the specimen as shown in Figure 2.

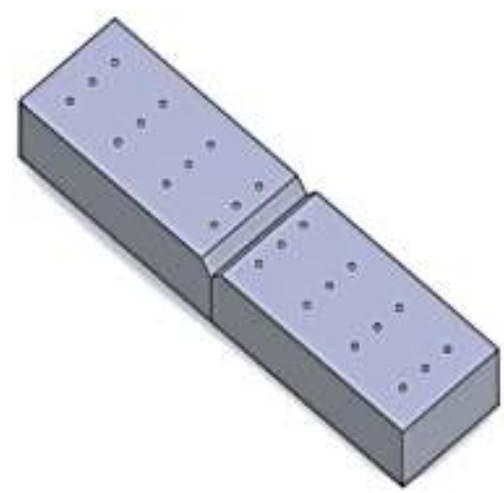

(a) CAD Model

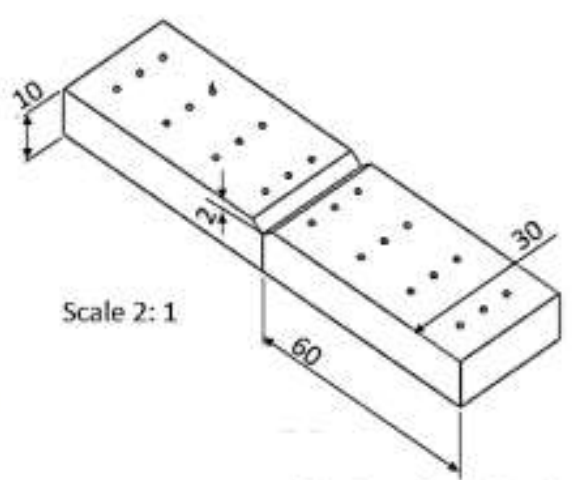

(b) Plate Dimension (mm)

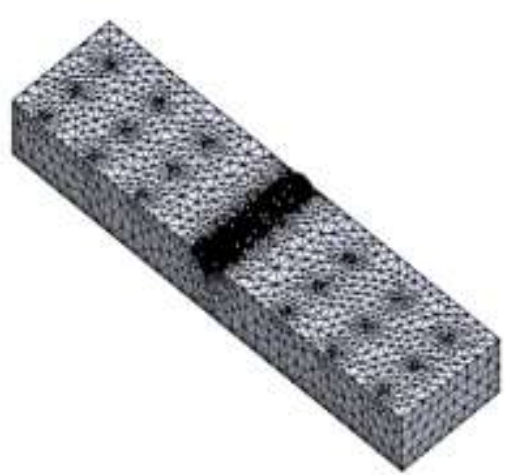

(c) Mesh Visualization

Figure 2. AISI 1020 low carbon steel plate developed with SOLIDWORKS.

However, mesh control was applied to the heat source, while curvature based mesh was used due to the ellipsoidal shape of the heat source. The model information is presented in Table 2. The simulation was run for 20 runs designed by using the design of experiment (Centre Composite Design Method). 
Table 2. Model information for AISI 1020 low carbon steel plate.

\begin{tabular}{llll}
\hline Model Information for 10 mm Flat Plate & & \\
\hline Study name: & TIG WELDING & Mesher Used: & Curvature based mesh \\
Analysis type: & Thermal (Transient) & Jacobian points: & 4 Points \\
Mesh type: & Solid Mesh & Maximum element size: & $3.4556 \mathrm{~mm}$ \\
Solver type: & FFEPlus & Minimum element size: & $0.69112 \mathrm{~mm}$ \\
Solution type: & Transient & Total Nodes: & 218728 \\
Total time: & 20 Seconds & Total Elements: & 154350 \\
\hline
\end{tabular}

\section{RESULTS AND DISCUSSION}

The experimental welding procedure was carried out on $10 \mathrm{~mm}$ AISI 1020 low carbon steel plate using TIG welding approach while the finite element simulation was developed using Solid Works thermal transient flow interface. In this paper, the residual stresses induced on the weldment during the experimentation and FEM were measured as shown in Table 3; while the plot of experimental and FEM predicted residual stress values are presented in Figure 3. The weld-induced residual stress fields along several regions at each weld (point) were also investigated by numerical simulations based on FEM modelling, with the graphical view presented in Figure 4. Each colour on the line graph represents induced stress distributions across various welding points of the welded joint. However, the thermal induced residual stress distribution profile at variable temperature ranging from $230-563^{\circ} \mathrm{C}$ is shown in Figure 5-16 respectively. From the stress profiles, the maximum residual von-Mises stress at specific temperatures is presented in Figure 17.

Table 3. Experimental and FEM predicted results.

\begin{tabular}{llllllll}
\hline \multicolumn{2}{l}{ Design of Experiment } & \multicolumn{3}{l}{ Experimental } & \multicolumn{2}{l}{ Finite Element Method } \\
\hline $\begin{array}{l}\text { No of } \\
\text { Runs }\end{array}$ & $\begin{array}{l}\text { Current } \\
\text { Amp }\end{array}$ & $\begin{array}{l}\text { Voltage } \\
\text { Volts }\end{array}$ & $\begin{array}{l}\text { Gas Flow Rate } \\
\text { (L/min) }\end{array}$ & $\begin{array}{l}\text { Temperature } \\
{ }^{\circ} \mathrm{C}\end{array}$ & $\begin{array}{l}\text { Experimental } \\
\text { Residual } \\
\text { Stress (MPa) }\end{array}$ & $\begin{array}{l}\text { Temperature } \\
{ }^{\circ} \mathrm{C}\end{array}$ & $\begin{array}{l}\text { FEM } \\
\text { Residual } \\
\text { Stress } \\
(\mathrm{MPa})\end{array}$ \\
\hline $\mathbf{1}$ & & & & & & 308.22 \\
$\mathbf{2}$ & 155.00 & 22.00 & 15.50 & 298 & 309.86 & 286.32 & 309.88 \\
$\mathbf{3}$ & 155.00 & 22.00 & 15.50 & 287 & 314.56 & 288.43 & 307.23 \\
$\mathbf{4}$ & 155.00 & 22.00 & 15.50 & 265 & 303.76 & 272.77 & 324.54 \\
$\mathbf{5}$ & 155.00 & 22.00 & 15.50 & 264 & 317.21 & 280.28 & 366.21 \\
$\mathbf{6}$ & 155.00 & 22.00 & 15.50 & 265 & 317.02 & 284.44 & 366.41 \\
$\mathbf{7}$ & 155.00 & 27.05 & 15.50 & 265 & 316.33 & 283.79 & 387.66 \\
$\mathbf{8}$ & 96.14 & 22.00 & 15.50 & 319 & 314.37 & 370.13 & 233.47 \\
$\mathbf{9}$ & 155.00 & 22.00 & 11.30 & 393 & 144.54 & 235.354 & 349.99 \\
$\mathbf{1 0}$ & 155.00 & 16.95 & 15.50 & 300 & 337.45 & 340.742 & 296.42 \\
$\mathbf{1 1}$ & 213.86 & 22.00 & 15.50 & 423 & 300.21 & 290.104 & 474.32 \\
\hline
\end{tabular}




\begin{tabular}{llllllll}
\hline $\mathbf{1 2}$ & 155.00 & 22.00 & 19.70 & 253 & 396.95 & 426.288 & 374.73 \\
$\mathbf{1 3}$ & 120.00 & 19.00 & 18.00 & 251 & 340.27 & 275.112 & 311.62 \\
$\mathbf{1 4}$ & 190.00 & 19.00 & 13.00 & 265 & 297.99 & 360.218 & 343.00 \\
$\mathbf{1 5}$ & 190.00 & 25.00 & 13.00 & 354 & 402.36 & 471.247 & 433.34 \\
$\mathbf{1 6}$ & 120.00 & 25.00 & 18.00 & 308 & 263.31 & 359.245 & 366.33 \\
$\mathbf{1 7}$ & 190.00 & 25.00 & 18.00 & 423 & 427.16 & 563.779 & 477.88 \\
$\mathbf{1 8}$ & 120.00 & 19.00 & 13.00 & 325 & 275.88 & 230.72 & 268.32 \\
$\mathbf{1 9}$ & 120.00 & 25.00 & 13.00 & 378 & 249.27 & 300.817 & 324.92 \\
$\mathbf{2 0}$ & 190.00 & 19.00 & 18.00 & 380 & 327.19 & 430.535 & 414.52 \\
\hline
\end{tabular}

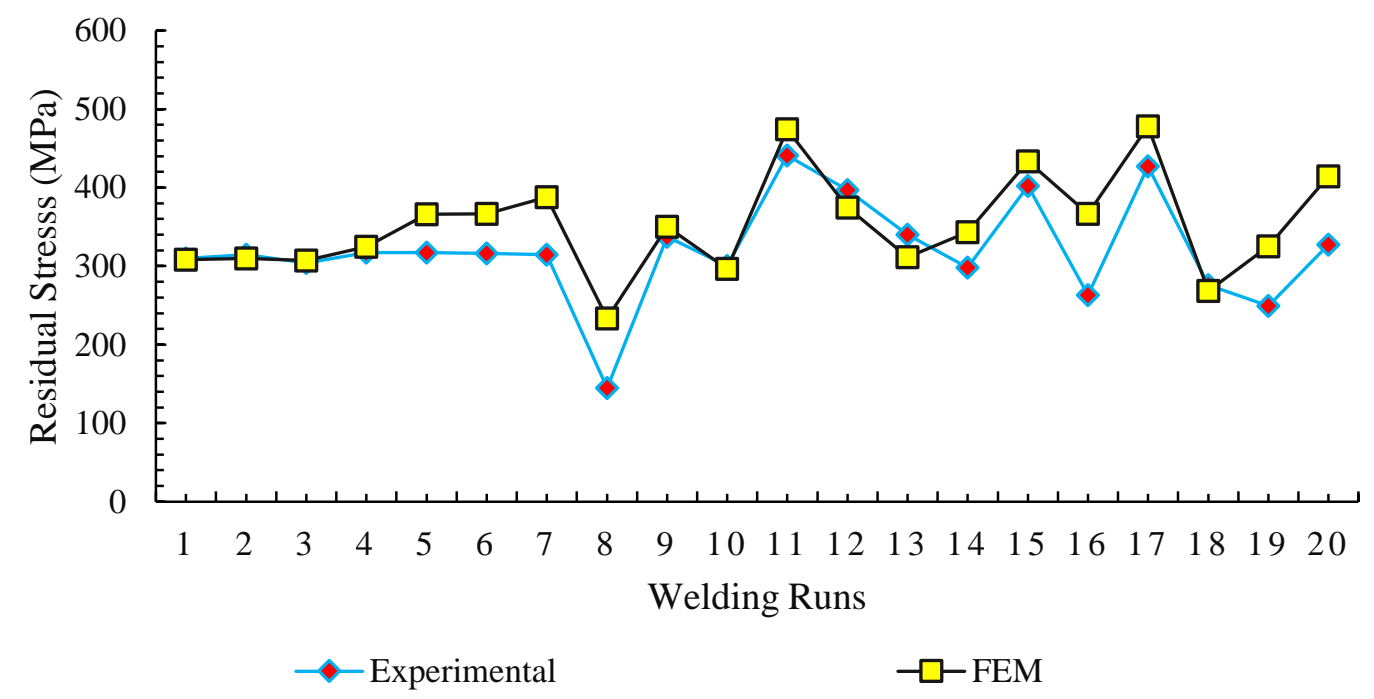

Figure 3. Plot of experimental and FEM predicted residual stress.

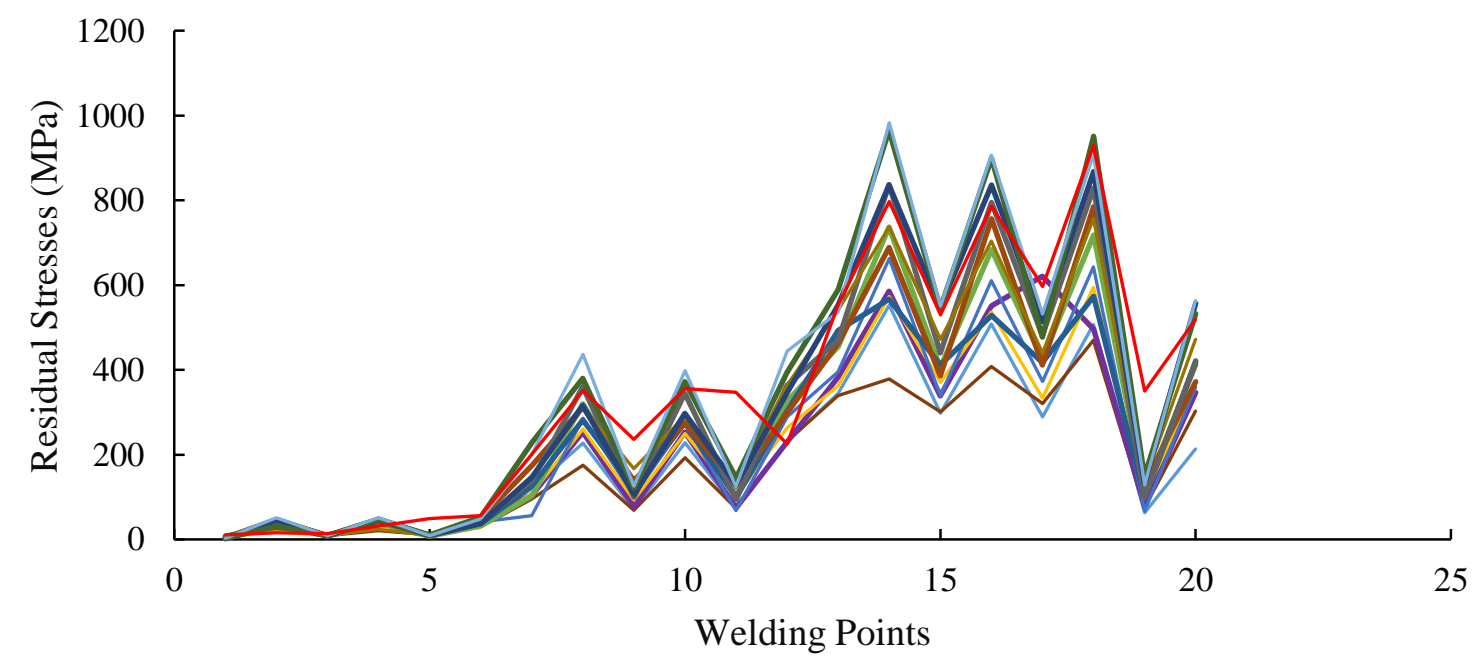

Figure 4. Plot of FEA predicted residual stress on several regions on each point weldment. 


\section{Induced Stress Distribution}

The results of the induced stress distribution was created from a static study where the thermal results were used as the loading conditions. The ends of the flat plat and its base were fixed to avoid displacement and twenty different runs were carried out using the temperature effect from the thermal study. For better visualization of the residual induced stress distribution, only one half of the welded metal was extracted from the simulation since the stresses were distributed evenly across the two plates as shown in Figure 5-16.
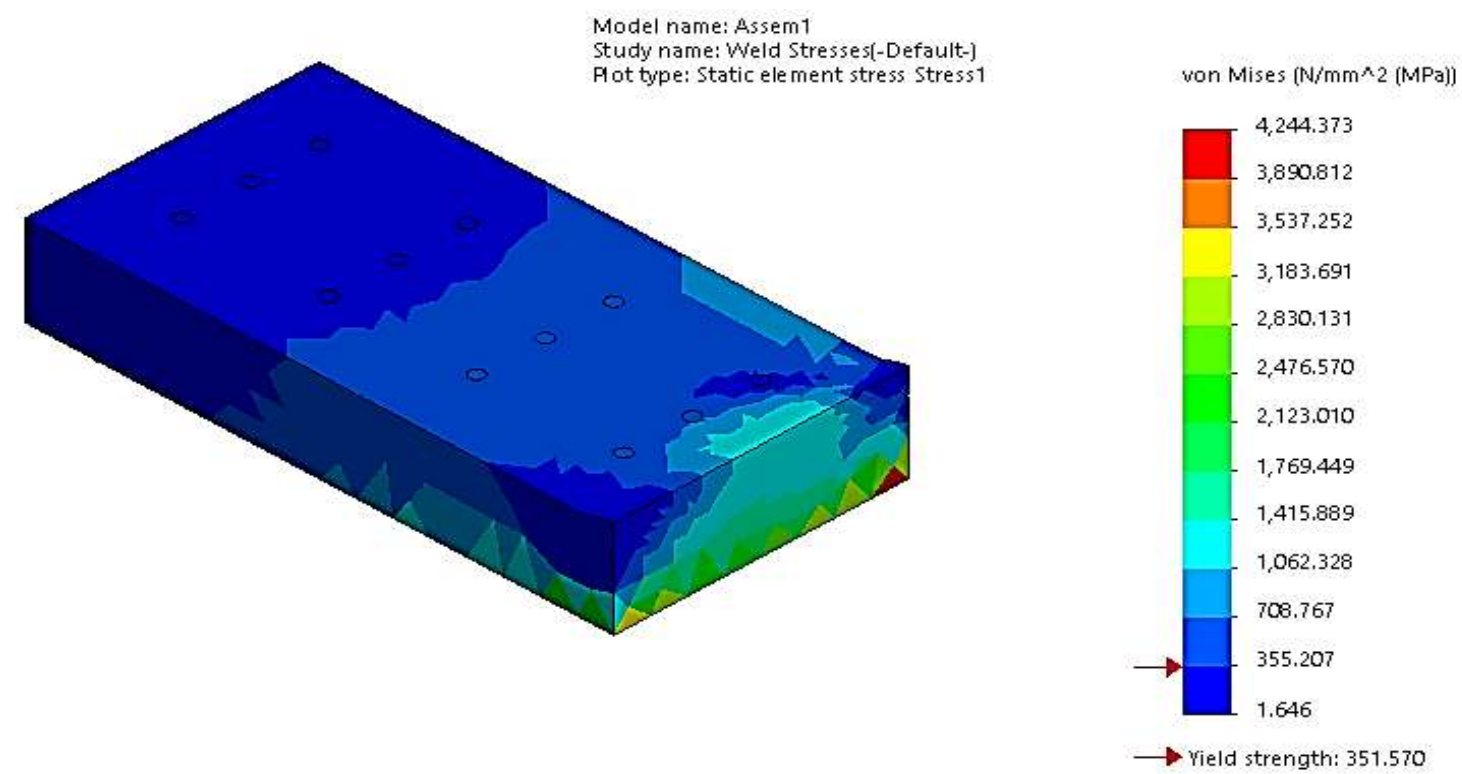

Figure 5. Induced stress plot at temperature gradient of $230.72{ }^{\circ} \mathrm{C}$.
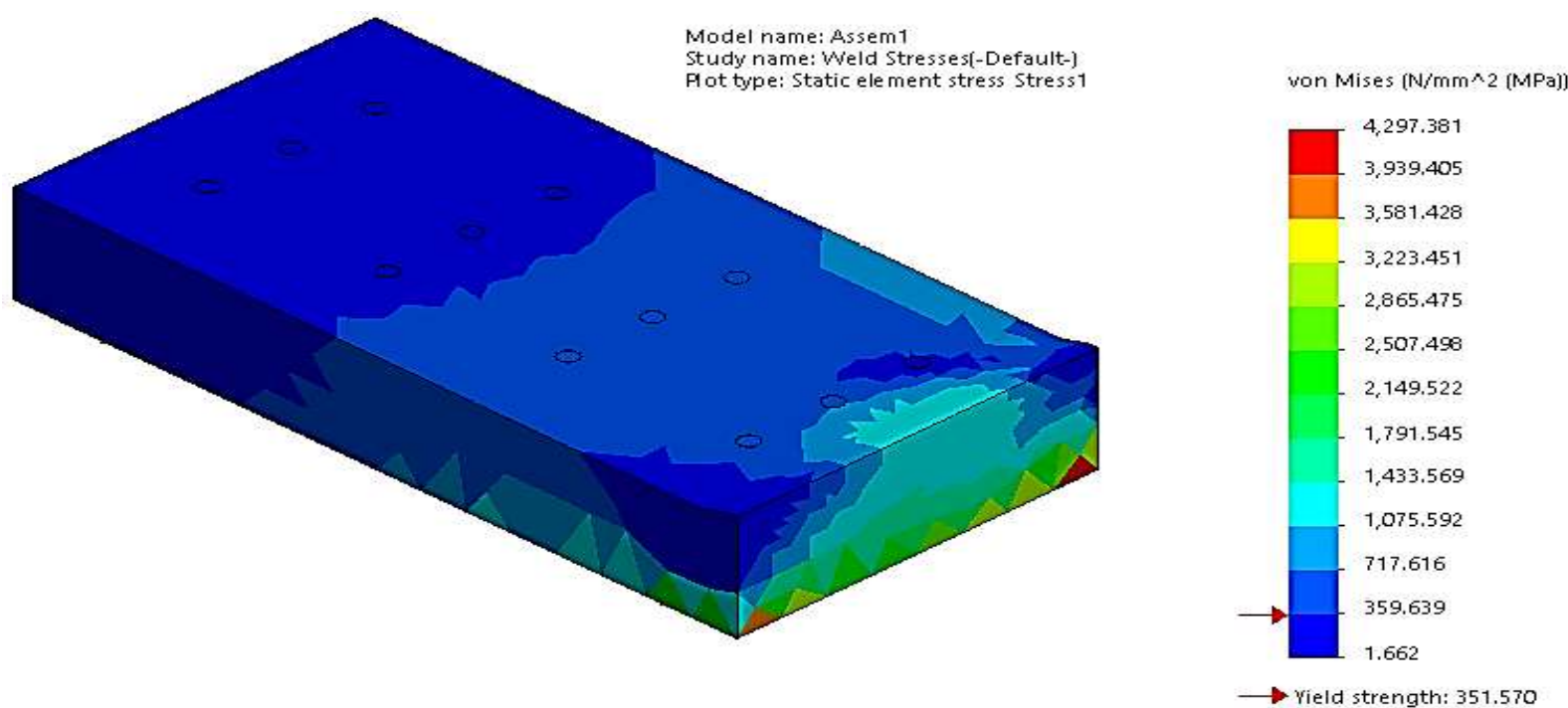

Figure 6. Induced stress plot at temperature gradient of $235.314{ }^{\circ} \mathrm{C}$. 

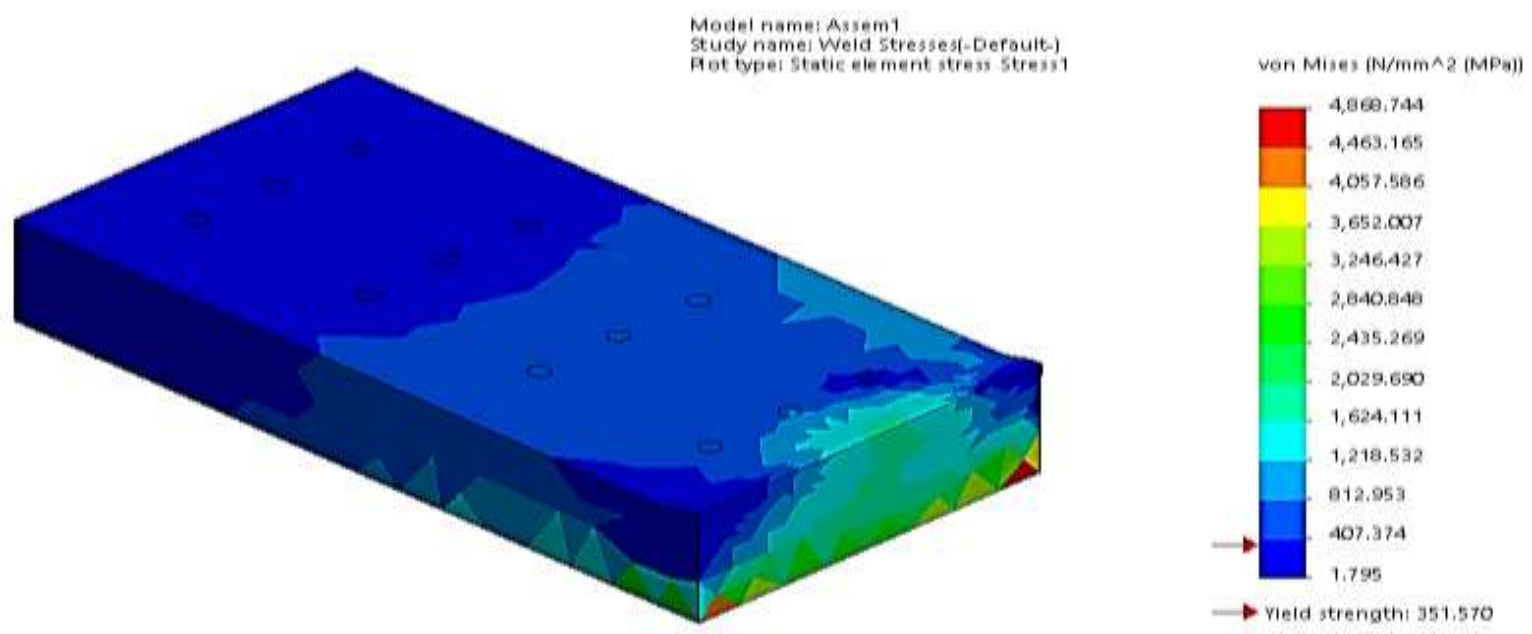

Figure 7. Induced stress plot at temperature gradient of $275.112^{\circ} \mathrm{C}$.
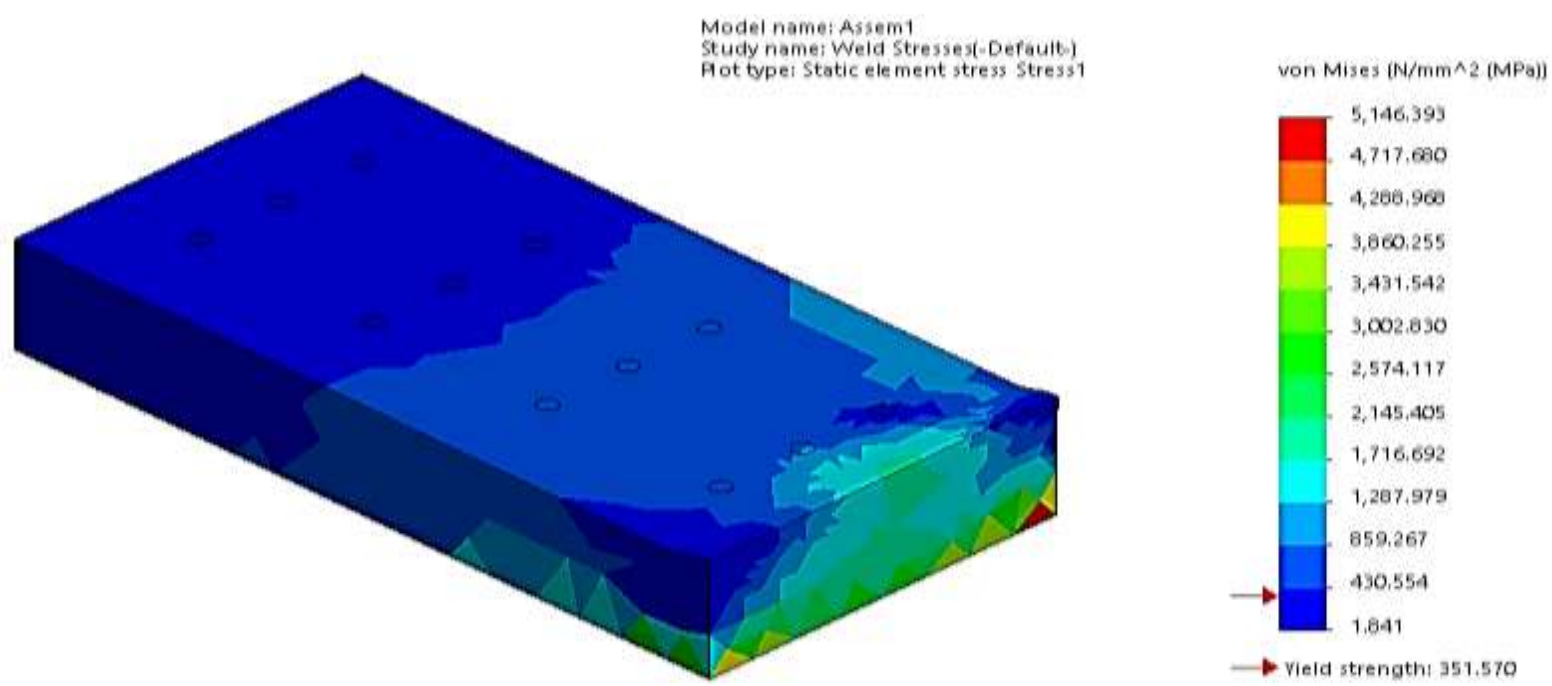

Figure 8. Induced stress plot at temperature gradient of $290.104{ }^{\circ} \mathrm{C}$. 


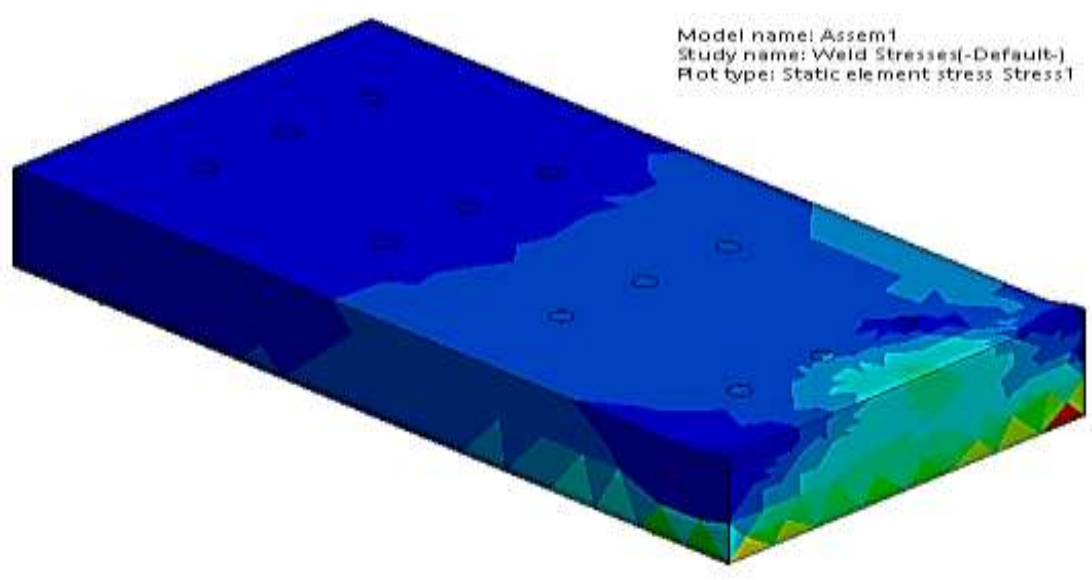

Figure 9. Induced stress plot at temperature of $300.817^{\circ} \mathrm{C}$.

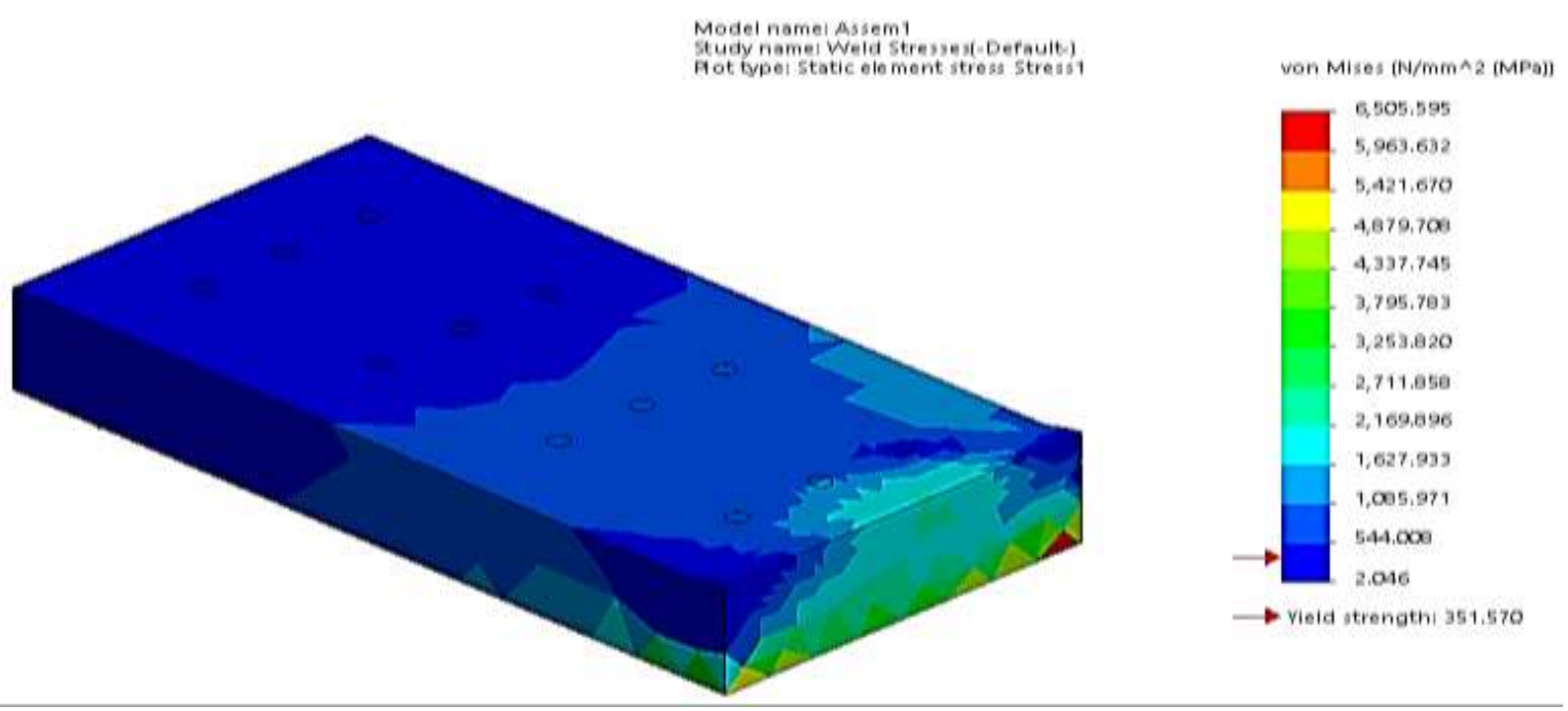

Figure 10. Induced stress plot at temperature gradient of $360.218{ }^{\circ} \mathrm{C}$. 

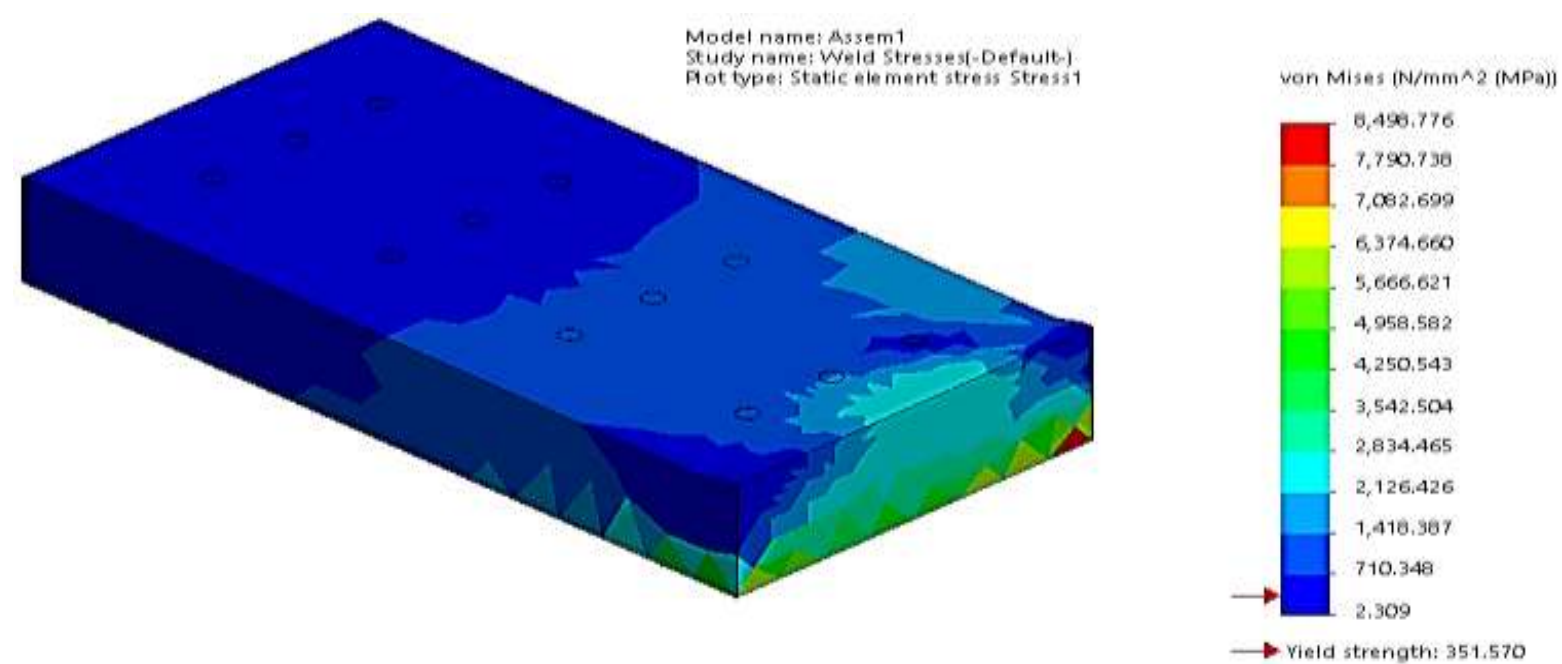

Figure 11. Induced stress plot at temperature gradient of $370.13{ }^{\circ} \mathrm{C}$.
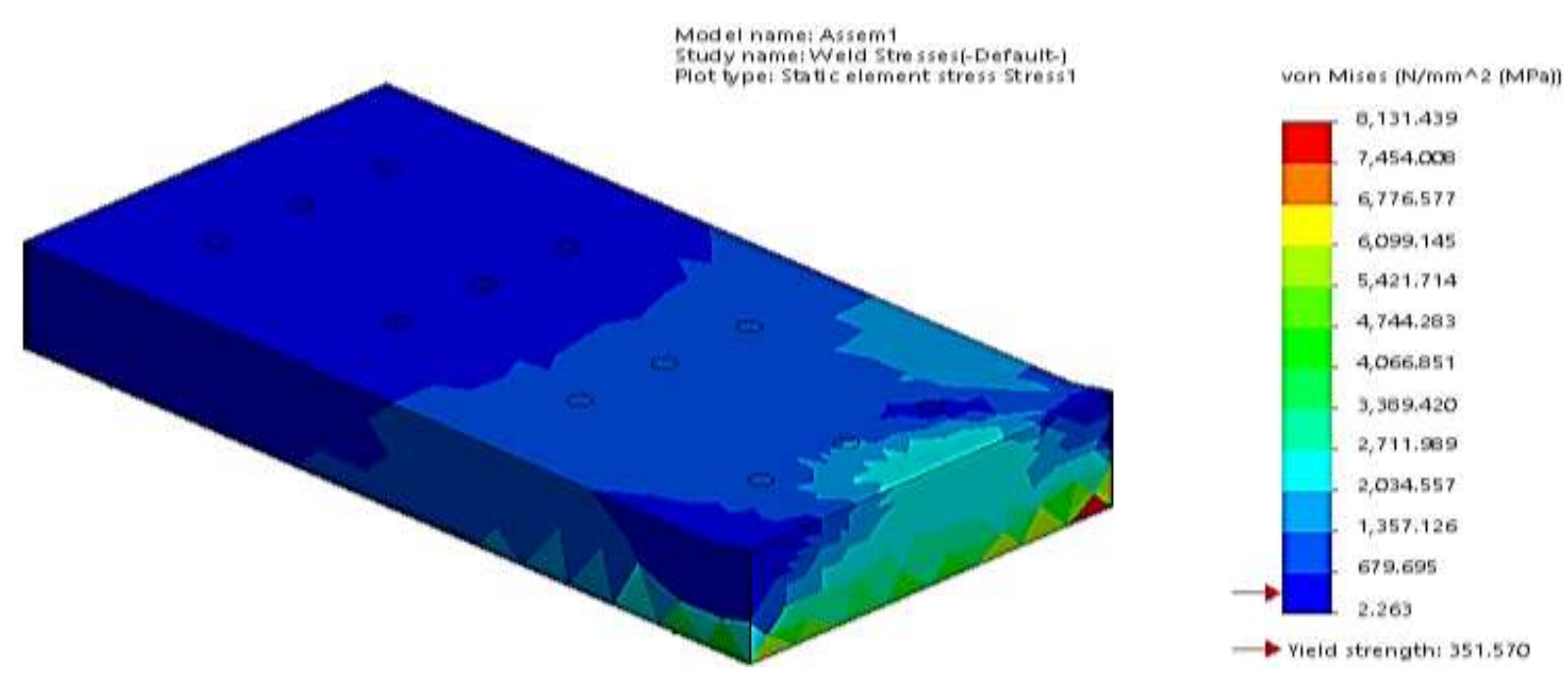

Figure 12. Induced stress plot at temperature gradient of $426.288^{\circ} \mathrm{C}$. 

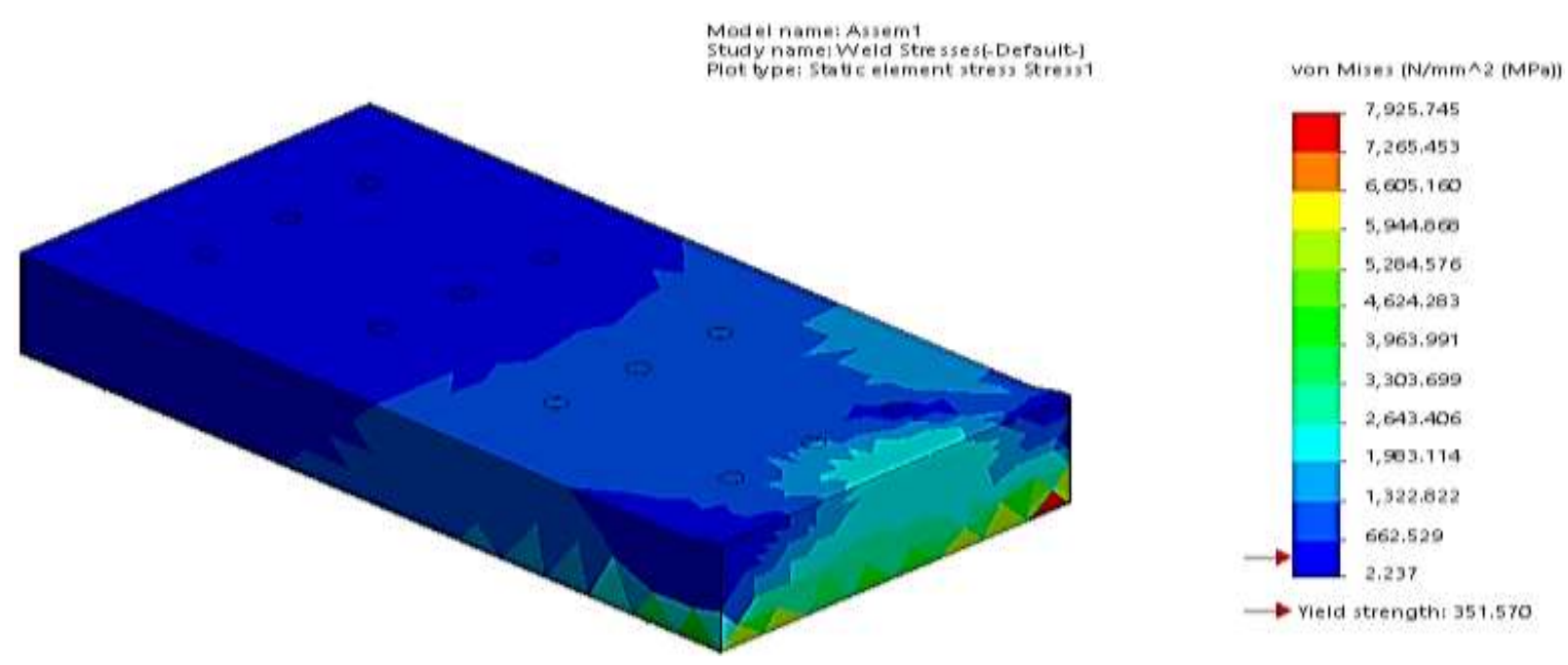

Figure 13. Induced stress plot at temperature gradient of $430.535{ }^{\circ} \mathrm{C}$.

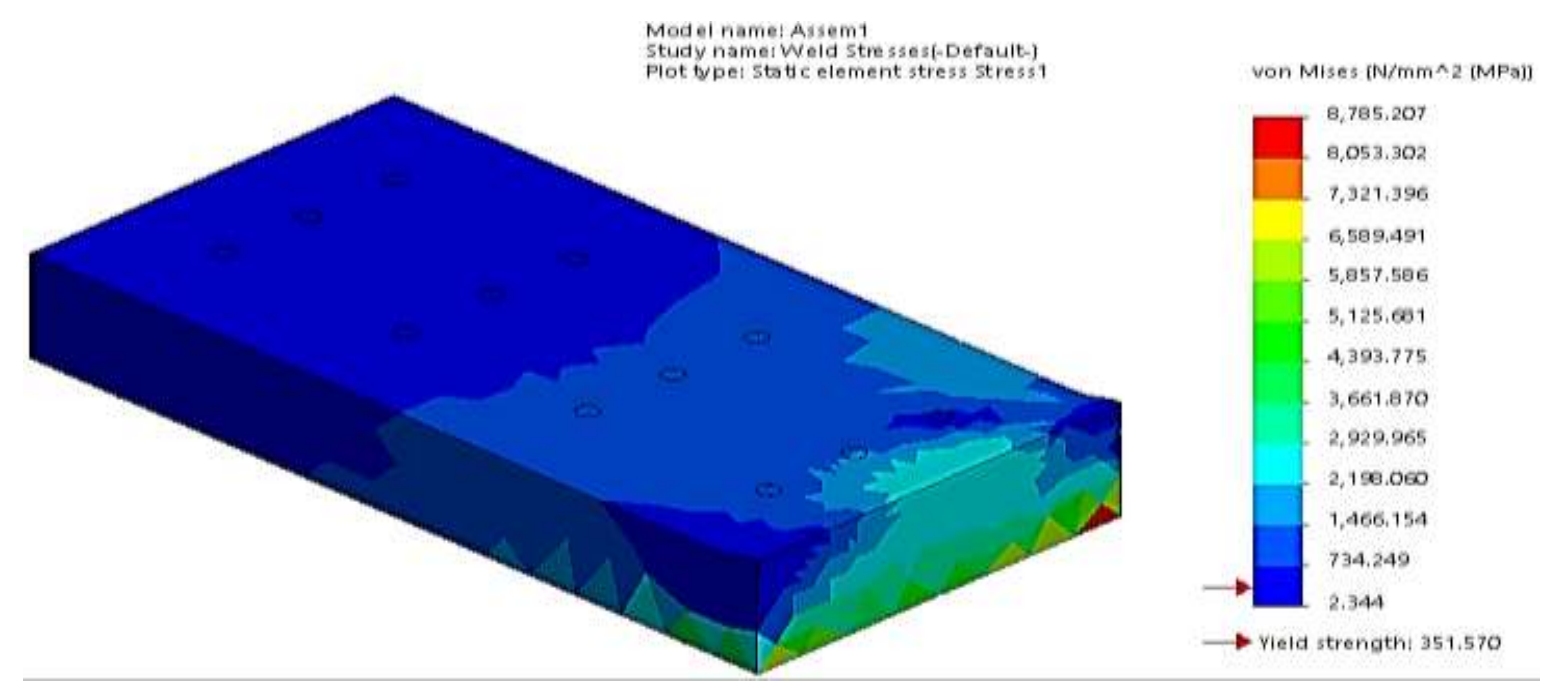

Figure 14. Induced stress plot at temperature gradient of $471.247^{\circ} \mathrm{C}$. 


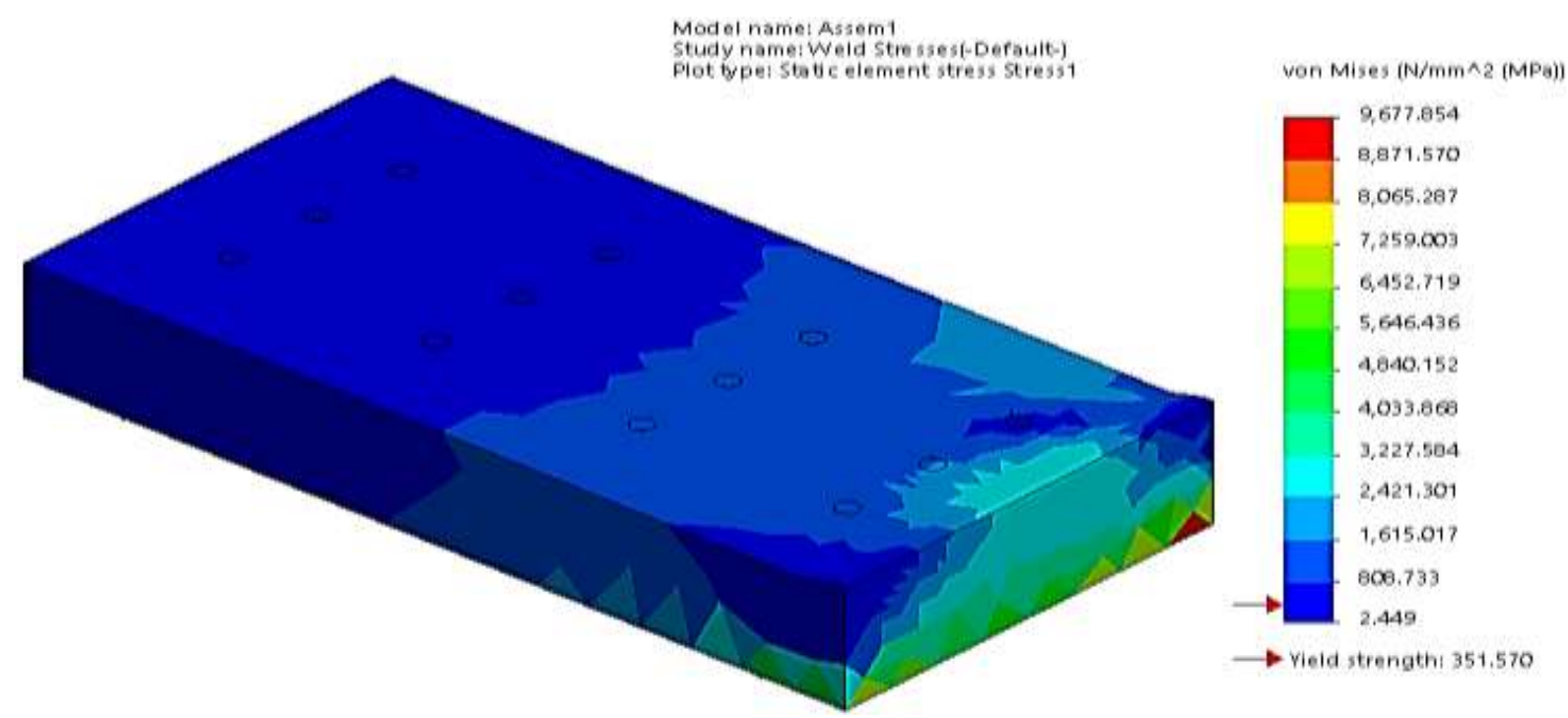

Figure 15. Induced stress plot at temperature gradient of $512.681{ }^{\circ} \mathrm{C}$.
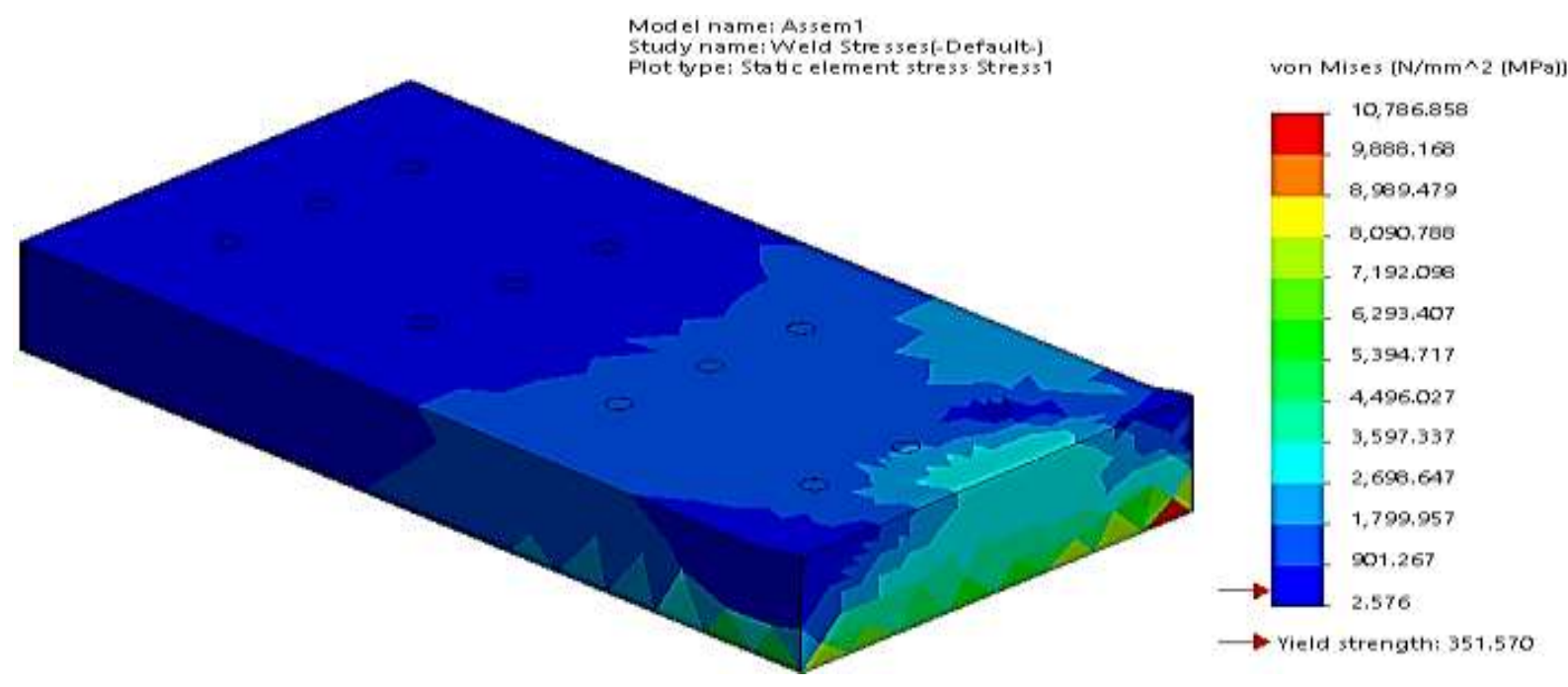

Figure 16. Induced stress plot at temperature gradient of $563.779{ }^{\circ} \mathrm{C}$. 


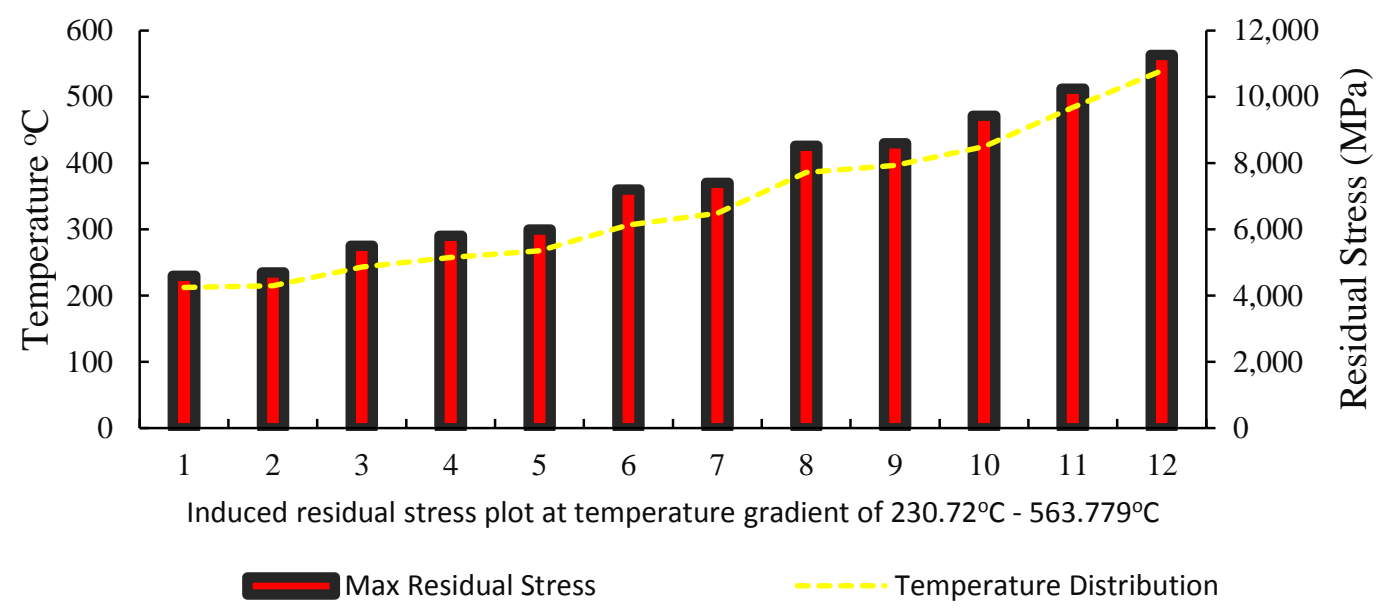

Figure 17. Plot of temperature with corresponding maximum residual stress.

As shown in Table 3, not much differences were observed at each welding point in terms of variations between the temperature and stress results obtained from the TIG welding experimentation and the FEM. The results obtained from each welding runs for both welding methods produced stress and temperature variations with no specific trend, as some of the values increased while some decreased at each point.

The thermal transient flow of the molten metal at the weld pool during fusion of the steel plates indicated possible stress distribution across the weldment of which an increase or decrease in the stress values has a resulting effect on the weldment. As shown in Figure 4, graphical representation of the aforementioned induced stress distribution at each welding point showed no specified direction due to the material response to heat transfer and cooling in the welding sequence. However from the residual stress distribution plot in Figure 4, the residual stress distribution curves though characterised by irregular patter were somewhat increasing as the welding points extended further, thus the 2.5 seconds welding sequence could sustain the heat energy within the weldment but for relatively short time before cooling, but increasing the arc welding time will consume more electrode, power and above all will induce more stress and cause spatter on the material surface.

To adequately delineate the complex phenomenon resulting from the tungsten inert gas welding process, a complete 3D model of the AISI low carbon steel plates was employed. Using Solid Works FE solver, transient, non-linear thermal solution based on the principles of heat conduction, convective and radiative boundary conditions was resolved at the initial phase of the simulation to obtain the required nodal temperature history. Selecting curvature based mesh as the mesher and FFEPlus as the solver in the thermal transient solution, discretization of the flat plate alongside with the mesh refinement along the welded region allowed for accurate prognostication of temperature and corresponding residual stress distribution across the steel plate. In other words, the temperature profiles were considered as thermal loads in the statically dependent analysis to obtain residual stress fields.

Applying FEM on the thermal analyses also served as a means of determining the residual stress component in the steel plate. In real life scenario, the welding process is a thermal cycle that starts from heat transfer from the welded region (forming a clouded region known as Heat Affected Zone) followed by heat distribution around the weldment and 
extending across the welded plate. Considering a time domain of 2.5 seconds for which each welding step was carried out, the stress distributions were observed to concentrate more at the contours around the weldment. However, it was also found that the maximum residual von-mises stress point for each of the stress profile were at the sharp edges (and corners) demarcating the horizontal and vertical planes on the flat plates (as shown in Figure 5-16), where the two flat steel plates were fused together by TIG welding process. In addition, from the stress profiles, the von-misses residual stresses increased as the welding temperature increased as shown in the stress profiles in Figure 17.

The TIG welding process carried in this study involved a control deposition of molten metal between two cold parent metal plates. Immediate after each welding sequence, it was observed that as the welded joint cooled the weld metal contracted but was restrained by the cold metal on either sides. This led to increase in residual stress in the weldment as the temperature gradually decreased. However, when the stress had reached a sufficiently high value (yielding point) the metal deformed plastically due to creep mechanism.

Considering the effects of creep mechanism also known as thermal loading of welding temperature on the geometry, properties, microstructure and general behaviour of the material; the aforementioned thermal induced stresses are trapped within the weldment as residual stress which can increase the risk of brittle fracture by providing a driving force for crack propagation or stress corrosion cracking that may result in unforeseen failure of the welded joint in service condition. This is because, the steel plate is acted upon by other external forces such as compressive and tensile if subjected to severe operation sequence which in turn would interact with the residual stresses trapped within the material, thus, increasing the component duty cycle, tending to exceed the material endurance limit, causing stress nucleation, propagation, cracks and possible exposure to premature failure. Residual stress functions with the principles of maximum distortion energy criterion (also referred to as von-Mises yield criterion) which is part of plasticity theory for ductile materials, suggesting that the yielding effect of a given material commences when the second deviatoric stress invariant reaches a critical value. Two methods are usually adopted for minimizing the residual induced stress in the weldment namely, thermal and mechanical post-weld treatment [20-21]. The primary purpose of stress relieving the welded material is to obtained dimensional stability that would provide tolerances during machining sequence, to produce the required metallurgical structures required to achieve optimum mechanical properties and also to minimize the risk of exposing the welded metal to stress corrosion or brittle fracture in service condition.

For the post-weld thermal heat treatment of low carbon steels, the metal is heated to a temperature range of $1100^{\circ} \mathrm{C}-1350^{\circ} \mathrm{C}$ where reduction in the yield strength of the material is observed to be proportional to the residual stress, thereby, reliving the induced stress within the metal. However for mechanical post-weld treatment, shot peening or vibratory method can be adopted for relieving induced stresses. Shot peening is a cold working process that uses projected shot round metal balls on the surface of the weldment during which small indentations are imparted into the surface of the weldment to induce compressive stress [22]. Emphatically, tensile residual stresses present at the surface of the weldment must "surmount" for fatigue crack initiation to occur. In other words, compressive stresses resulting from the shot peening effects will counteract the tensile residual stresses at the surface of the weldment if adequately carried out; but surface compressive stress, maximum compressive stress, depth of compressive stress, velocity of shots must be properly 
controlled, as too deep the shot impingement may result in damaging induced stresses that may negate the desired result. The vibratory method implies attaching a mechanical vibrating machine to the weldment during which the vibration's resonance frequency is controlled, thereby unifying induced stress distribution within the weldment via plastic deformation of the material grain sizes which in turn reduces sharp stress peaks in the lattice structure of the material.

\section{CONCLUSION}

All welds are prone to some residual stresses, and it is more or less impossible to completely reduce the weldment to zero stress. However, Induced stress level can be intense due to certain welding conditions such as heat input, type of welding, thickness of base metal, cooling rate, welding parameters etc. FEM (233-477MPa) and experimentally (144-402MPa) determined residual stresses as well as the FEM $\left(230^{\circ} \mathrm{C}-563^{\circ} \mathrm{C}\right)$ and experimentally $\left(251^{\circ} \mathrm{C}\right.$ $423^{\circ} \mathrm{C}$ ) induced on AISI 1020 low carbon steel plate during tungsten inert gas welding process in this study revealed that both methods are suitable, but the residual stress and temperature values obtained must be optimised to achieve distortion free weldments. Results of the induced stress distribution created from static study where the thermal results were considered as loading condition also pointed out that a piece of material subjected to loading due to thermal or static condition will undergo distortion and possible deformity as the loading sequence increases. To prevent unforeseen failure in service conditions of welded metals, thermal or mechanical post-weld treatment may be carried out to relief the stresses induced within the welded metal.

\section{ACKNOWLEDGEMENTS}

The authors would like to acknowledge Engr. Victor Omigie for his Contribution and time towards the successful completion of this research. (Project No. pg2015_548852).

\section{REFERENCES}

[1] Wor LC, Rahman MM, Stress Behaviour of Tailor-Welded Blanks for Dissimilar Metals Using Finite Element Method. International Journal of Automotive and Mechanical Engineering 2015;11:2541-2554.

[2] Yaakob KI, Ishak M, Idris SR, The Effect of Pulse Welding Parameters on Weld Geometry of Boron Steel Using Low Power Fibre Laser. Journal of Mechanical Engineering and Sciences 2017;11:2895-2905.

[3] Razak NA, Shing SN, Investigation of Effects of MIG Welding Corrosion Behaviour of AISI 1010 Carbon Steel. Journal of Mechanical Engineering and Sciences 2014;7:1168-1178.

[4] Nuraini AA, Zainal AS, Hanim MA, The effects of Welding Parameters on Butt Joints Using Robotic Gas Metal Arc Welding. Journal of Mechanical Engineering and Sciences 2014;6:988-994. 
[5] Ghazali FA, Manurung YH, Mohamed MA, Alias SK, Abdulla S, Effect of Process Parameters on the Mechanical Properties and Failure Behaviour of Spot Welded Low Carbon Steel. Journal of Mechanical Engineering and Sciences 2015;8:1489-1497.

[6] Ikpe AE, Owunna I, Ememobong, I, Effects of Arc Voltage and Welding Current on the Arc Length of Tungsten Inert Gas Welding (TIG). International Journal of Engineering Technologies 2017;3:213-221.

[7] Ravichandran M, Sait AN, Vignesh U, Investigation on TIG Welding Parameters of 2205 Duplex Stainless Steel. International Journal of Automotive and Mechanical Engineering 2017;14:4518-4530.

[8] Deng D, Luo Y, Serizawa H, Shibahara M, Murakawa, H, Numerical Simulation of Residual Stresses and Deformation Considering Phase Transformation Effect. Transactions of Joining and Welding Research Institute 2003;32:325-333.

[9] Tsai C, Kim D, Understanding residual stresses and distortion in welds: an overview. Processes and mechanisms of welding residual stresses and distortion. In: Feng Z, Processes and mechanisms of welding residual stresses and distortion. CRC Press, Florida. 2005;3-6.

[10] Radaj D, Welding residual stresses and distortion: calculation and measurement $2^{\text {nd }}$ edn. Verlag für Schweissen und Verwandte Verfahren, DVS-Verlag. 2003;118-200.

[11] Zain-ul-Abdein M, Nelias D, Jullien J, Deloison D, Prediction of Laser Beam Welding-Induced Distortions and Residual Stresses by Numerical Simulation for Aeronautic Application. Journal of Materials Processing Technology 2009;209:2907-2917.

[12] Yaghi A, Becker A, State of the Art Review-Weld Simulation Using Finite Element Method. University of Nottingham, UK, Report No: FENET-UNOTT-DLE-08. 2004; 1-27.

[13] Wei L, Junjie M, Fanrong K, Shuang L, Radovan K, Numerical Modelling and Experimental Verification of Residual Stress in Autogenous Laser Welding of HighStrength Steel. Lasers in Manufacturing and Materials Processing 2015;2:24-42.

[14] Qian Z, Chumbley S, Johnson E, The Effect of Specimen Dimension on Residual Stress Relaxation of Carburized and Quenched Steels. Materials Science and Engineering: A 2011;529:246-252.

[15] Mohamed SA, Abdulla S, Arifin A, Arifin AK, Padzi MM, Characterization of the Biaxial Fatigue Behaviour on Medium Carbon Steel Using the Strain-life Approach. International Journal of Automotive and Mechanical Engineering 2016;13: 32623277.

[16] Taylor GA, Hughes M, Strusevich N, Pericleous K, Finite Volume Methods Applied to the Computational Modelling of Welding Phenomena. Applied Mathematical Modelling 2002;26:309-320.

[17] Minh PS, Phu TV, Study on the Structure Deformation in the Process of Gas Metal Arc Welding (GMAW). American Journal of Mechanical Engineering 2014;2:120124.

[18] Goldak JA, Akhlaghi M, Computational Welding Mechanics. Springer, New York, USA. 2005; 9780387232881.

[19] Goldak J, Chakravarti A, Bibby M, A New Finite Element Model for Welding Heat Source. International Journal Metallurgical and Materials Transactions B 1984;15:299-305. 
[20] Paradowska AM, Zhao X, Stress Relieving and its Effect on Life of Welded Tubular Joints. Engineering Failure Analysis 2010;17:320-327.

[21] Kang HT, Lee Y, Sun XJ, Effects of Residual Stress and Heat Treatments on Fatigue Strength of Weldments. Material Science and Engineering: A 2008;497:37-43.

[22] Hatamleh O, Rivero I, Lyons, J, Evaluation of Surface Residual Stresses in Friction Stir Welds due to Laser and Shot Peening. Journal of Materials Engineering and Performance 2007;16:549-553. 